experienced obstetric radiologist, the method has been found to be over $80 \%$ accurate in predicting light-for-dates babies in the cases so far reviewed.

It is therefore appropriate to $x$-ray those fetuses which are thought to be growth retarded, either on clinical assessment or following screening procedures, not only as a further method of confirming the diagnosis by estimating the "fetal fat percentile" but also to exclude gross abnormalities (for example, thanatophoric dwarfism ${ }^{2}$ and severe osteogenesis imperfecta ${ }^{3}$ ) commonly associated with the small fetus.

G J LEWIS

Department of Obstetrics and Gynaecology, St Mary's Hospital,

Russell JGB. Radiology in obstetrics and antenatal paediatrics. London: Butterworths, 1973:222. Maroteaux P, Lamy M, Robert JM. Presse médicale 1967;49:2519-24.

${ }^{3}$ Felisaz GL. Bulletin de la Fédération des Sociétiés de Gynaécologie et d'Obstétrique de Langue Francaise 1963;15:656-7.

\section{Cutting the cost of the National Health Service}

SIR,-There has been a series of provocative articles in the $B M \mathcal{A}$ about how to cut costs in the National Health Service. ${ }^{1}$ Dr Maurice Pappworth has spread himself to the extent of 10 full pages in World Medicine. ${ }^{2}$ And now we have Dr G N Marsh, (3 May, p 1140), a general practitioner, with his "bald list" of economies-and pretty feeble some of them are. Most vitriol, naturally, has been expended on the well-known and reckless profligacy of those overpaid elitists the hospital consultants, who are bankrupting the country. I do no mind being labelled an elitist (or a perfectionist either, Mr Ennals-remember him ?): in fact, it makes me proud. But the way things are going I almost fear to leave the house.

The hospital service is the costly part of the NHS; it is an obvious Aunt Sally. If cuts are to be made that is where they will be made. The most expensive management decision ever taken in the NHS is to admit a patient to hospital. Who takes this decision? As often as not, it is taken by $\mathrm{Dr}$ Marsh and his costconscious fellow GPs. No one ever thinks to mention that.

Nor, when people rabbit on about how "cost effective" we ought to be (although how any illness can qualify for cost effectiveness is never satisfactorily explained), do they put their money where their mouths are. No one suggests that doctors should take a cut in salary, for example. The reverse, in fact "More work-more pay," exclaims Dr Marsh, whose entrepreneurial genius does not exten to making one single attempt-not one-to quantify his alleged savings. "Prescribing from outpatient departments should be abandoned and patients...told to see their general practitioner." The cost to the NHS of a drug prescribed by a GP is at least twice what it would be were it dispensed by a hospital outpatient pharmacy. There should be "earlier and earlier discharge (from hospital) or more surgical cases." All right: what happens to the vacated beds ? Going to stay empty, are they ?

Much of what Dr Marsh says is true and reasonable and sensible-self-evident, even. $\mathrm{He}$ is knocking on an open door. But does it not strike him that there are others of like views and of equal talent and goodwill? We are trying to cut costs; but we can only succeed if it is made crystal clear to us, in detail, just what those costs are. But it never is made clear. This is why Dr Marsh cannot put actual figures to his savings. $\mathrm{He}$ does not know any figures. And neither do I.

Four years ago I begged the authoritiesbegged them-to estimate the cost of running our department of anaesthetics. Four years. And I am no nearer to finding out now than I was then. Why not? "It costs too much." I have asked time and again for a departmental functional budget. I still have no functional budget. Why not? "It costs too much." We have asked for a fixed percentage of the district's assets to be spent on equipment. We have been refused. My colleagues and I were reprimanded for being "grossly overspent" on drugs. As usual, no financial details were made available. The regional health authority's expenditure on drugs was $2.7 \%$ of its revenue budget. My colleagues' expenditure, it eventually turned out, was $2 \cdot 76 \%$ of the district's revenue budget.

I sometimes feel that I am in a minority of one. Surely I cannot be the only person to perceive the reason behind these profitless and circular arguments about NHS costs? Their purpose is to obfuscate and distract attention from the real issue: the proportion of the gross national product devoted to health. Dr Marsh must be one of what we can only hope are the few, the very few, who actually glory in our pitiful rating at the bottom of the international league table. Perhaps he has been bamboozled by the academics and civil servants who lecture on King's Fund management courses. Whenever I point to this country's beggarly outlay on health, these persons always reply that more money would not necessarily improve the service. On the other hand, they never seem to follow this argument to its logical conclusion: perhaps we should be spending less. They never say that.

No. They never actually say it. But if you take the trouble to translate Patients First and its equally pernicious successor The Future Pattern of Hospital Provision in England ${ }^{3}$ you will see that this is what they really mean.

Division of Anaesthetics,

P V ScotT Bromsgrove General ${ }^{1}$ Anonymous. $B r$ Med $\mathcal{F} 1979$;ii :905-6, 985-6, 1057-8, Pappworth M. World Medicine 1980;15:39-57. Anonymous. $\mathrm{Br}$ Med F 1980;280:1335.

SIR,-Few would disagree with Dr G N Marsh's proposition (3 May, p 1140) that huge economies could be made in the NHS if doctors were to think more about their routines and rituals and improve their work methods. However, I profoundly disagree with some of his suggestions for saving money, and I would not wish them to pass without comment.

Change in public attitude-A major health education campaign would not only be an expensive waste of time, but in fact it would be dangerous. The early detection of serious illness depends on patients being encouraged to report their symptoms of what appears to them to be minor illness. Thus upper respiratory infections and diarrhoea may well be the first symptoms of a carcinoma of the lung and bowel. Patients should not generally be encouraged to cancel follow-up appointments because the doctor usually has a good reason for asking them to attend again, and it is not always appropriate to give reasons to the patient. I am strongly in favour of his suggestion for acquainting patients with the real cost of their treatment.

Medication-I agree with all the points made. Many hospitals are now limiting outpatient prescribing to two to four weeks, but to be effective the system requires close cooperation between hospital staff and general practitioners. Routine night sedation is quite unnecessary for the majority of hospital patients. Similarly, vast quantities of antibiotics are unnecessarily prescribed by general practitioners, often in homoeopathic dosage, for patients with minor, self-limiting sepsis. There is no doubt that many patients are suffering from iatrogenic illness as a result of becoming dependent on inappropriately prescribed psychotropic drugs-barbiturates and diazepam to name but two types.

Outpatients-Early referral of hospital patients back to their general practitioners is admirable in theory, but would not work in practice. Patients who have had surgery for breast and bowel cancer, bone sarcomas, and many other cancers may be receiving cytotoxic drugs and regular follow-up for careful screening is of vital importance for such patients. Patients who have had prosthetic replacements for one or more joints need similar careful examination by a doctor with specialist knowledge. In general it would not work because I doubt if general practitioners would make it their business to ensure that patients received a regular check-they would undoubtedly wait to be contacted by the patients, when it might be too late to help them. Furthermore, unless there is a sudden change in working methods, patients who need a domiciliary visit (they would normally come to outpatients by ambulance) will be told to make their way to the doctor's surgery. House officers do not generally see follow-up patients. Automatic discharge of these patients would be most inappropriate; many will be shown to the consultant because of problems (he cannot see all of them), and in any case it is clearly important for registrars in training to have some continuity of patient care.

Accident and emergency departments-I agree, as we all do, that accident and emergency departments should be used only by patients with accidents or general emergencies. Would Dr Marsh please tell me how you stop patients walking in (these are the majority) who say they cannot obtain or have no faith in their own general practitioner? Under no circumstances can they be sent away without being seen or examined by a doctor. General practitioners in many parts of London cannot be obtained for most of a 24-hour period unless the patient goes through a complicated, tiresome, and time-consuming answering service; if immediate contact is not possible, or there is to be a significant delay ( 15 minutes or more), then a distressed and anxious patient must be free to obtain an emergency ambulance without the need for a doctor's request.

Inpatients-Early discharge of surgical patients is practised wherever possible, and this process has accelerated because hospitals at long last are being asked to live within their budgets; however, it remains the consultant's responsibility to make certain that the community services are of an appropriate standard. Sadly, in many parts of London the deficiencies are such that it would be unwise to release the patient until all possible risks of complications are eliminated, and the elderly patients living alone are totally independent. I must again trouble Dr Marsh and ask him to tell me 
how you legislate to prevent junior staff ordering unnecessary investigations.

Notes and communications-Dr Marsh is on dangerous ground when he suggests drastic pruning of notes and abandoning ritualistic recording. The lawyers will confirm (and so will the defence societies) that the standard of clinical notes in hospitals leaves much to be desired. I spend a lot of time teaching, for sound medicolegal reasons, that more no less should be recorded in the notes. Communications between doctors are obligatory in the interest of the patients. We must be allowed to express our thoughts in our own particular style; the suggestion made by $\mathrm{Dr}$ Marsh would produce a serious deterioration in professional relationships, which sadly are not always of the highest standard.

I hope that Dr Marsh's stimulating article will have the effect for which it was no doubt written-namely, to stimulate debate on the most important and, until recently, neglected aspect of the NHS.

NIGEL H HARRIS

London W1

\section{What is "emergency"?}

SIR,-I am prompted to write this letter by the review (7 June, p 1372) of the textbook Accident and Emergency Medicine.

What a pity that the authors have perpetuated (p 3) the misconception about that noble, precise, and explicit word "casualty" contained in the Platt Report ${ }^{2}$ and should have given us, except in terms of the patients already there, no guidance on which "emergencies" are to go to the accident and "emergency" department-guidance so urgently called for in the Lewin Report. ${ }^{3}$ By giving the green light to the medical interpretation of the word "emergency" ( $p$ vii) we help to foster confused hysteria which seems here to be overtaking the profession.

Far from meaning the same thing (p 3 ) as accident and emergency, "casualty" was introduced into hospital administration 400 years ago $^{4}$ to designate those who, overtaken by some chance calamity, were immediately rendered "community dependent." Given the presence of illness, it was this "community dependence"-the need for immediate assistance from the independent citizen-which defined the function of our casualty departments; referral within the GP consultative service, more recently and laboriously established by our forebears, was for the family or domestic environment. There is a difference between renal colic at home and in the high street; and the importance of interpreting the word "emergency" in the newly titled accident and emergency departments sociologically-that is, in terms of attendant circumstances rather that in any medical context-was emphasised in the Casualty Surgeons' Association's evidence to the Royal Commission and the Expenditure Committee and in its Memorandum. ${ }^{6}$ Calnan's work ${ }^{7}$ adds weight to this evidence.

"Emergency" means precisely what the user wishes it to mean. For the patient every new symptom causes anxiety and may represent an "emergency" until he has a diagnosis. For the GP it means "out-of-hour" calls or those cases that require a same-day appointment, and for most consultants those admissions which cannot be arranged through outpatient consultations. Who is to tell the public, the DHSS, or the local committees (suggested by the authors) which "emergency" should go to hospital ? It has taken doctors years to learn to make the decision-and only when they see the case. So how is the layman to be told, much less a committee?

Have we accepted the principle of the hospital-based GP emergency service? Are our departments to become polyclinics (Russian style) or emergency rooms (American style)? We are already half way back to the "Dispensary Movement" with its horrors of overcrowding and 20 seconds a patient, the intruder - the "casualty"-waiting in one corner.

What will happen to our GP consultative service? Are GPs no longer to participate in treating anything remotely urgent? Should the nationwide telephone operator, receiving a domestic 999 call, or the casualty sister, not ask, "Have you tried your doctor ?" Who is to staff these open houses?

The authors are to be congratulated on the rest of the text. But I would really like to know what "accident medicine" is.

E P ABSON Chairman, Accident and Emergency Subcommittee,

Casualty Department, Kent and Canterbury Canterbury CT1 $3 \mathrm{NG}$

${ }^{1}$ Rutherford WH, Belson PG, Weston PAM, Wilson Wells: Pitman Medical 1980 .

2 Standing Advisory Medical Committee. Accident and emergency services. Report of the subcommittee. (Platt Report.) London: HMSO, 1962:23-5.

${ }^{3}$ Lewin W. Medical staffing and accident and emergency services. London: Joint Consultants Committee, 1978:2

${ }^{4}$ Copeland AJ. Bridewell Royal Hospital, past and present. Wells, Gardner, Dartar, and Co, 1888:35. ourth Report from the Expenditure Committe Session 1973-74: Accident and em
vol 1. London: HMSO, 1979:xvii.

Casualty Surgeons Association. An integrated emergency service. Casualty Surgeons Association, gency servi
$1973: 3-4$.

Calnan M. Pathways to the accident and emergency department. Canterbury: Health Services Research Unit, University of Kent, 1979.

${ }^{8}$ Loudon ISL. Br Med $\mathscr{f} 1978 ; \mathrm{i}: 974-7$.

\section{Multiple sclerosis in Africans}

SIR,-In $1970^{1}$ Dr J R Harries and I published a paper reporting two cases of multiple sclerosis occuring in Africans in Kenya. Because there were many reports about that time declaring that the disease was unknown in black Africans, our paper was published only after the opinions of other physician colleagues had been sought, and they were in agreement that the diagnosis was multiple sclerosis. Dr $\mathrm{R}$ Hoffenberg, reviewing $A$ Companion to Clinical Medicine in the Tropic and Sub-tropics by Professor E B Adams (5 January, p 36), stated that "multiple sclerosis is yet to be described in a black African." My co-author and I wish to disagree with him.

\section{St Mary's Hospital}

Newport, Isle of Wight PO30 5TG

${ }^{1}$ Foster R M, Harries J R. Br Med f 1970;iii:628.

\section{Motor neurone disease}

SIR,-Mr Roger Carus's Personal Paper (16 February, $p$ 455) made doubly distressing reading-firstly, because of his graphic description of the disease and, secondly, because he was nowhere told by the professional people he approached that the Muscular Dystrophy Group was, in fact, vitally concerned with motor neurone disease.

The Muscular Dystrophy Group covers, and has covered for some years, research into this and many other debilitating neuromuscular diseases; and we hope that gradually the organisation is becoming better known for this fact. Mrs Carus wrote to us in February last year, having discovered that the group financed research into neuromuscular diseases, and said in her letter that she felt there was something wrong with a system where doctors and social workers were unable to provide her with this information when it was needed. The simple reason for this is of course that most of the 40 or so diseases covered by the Muscular Dystrophy Group are relatively rare and therefore engender very little interest among general practitioners and social workers until a solitary case happens to impinge on them. There are therefore only a few specialists who can provide information and constructive advice for patients and for their families. This is the reason, surely, for the continued existence of voluntary agencies such as ours.

Because of the entirely understandable wish for better identification, a group of people has set up a-separate organisation, the Motor Neurone Association. However, it is inconceivable that research into every rare disease can be effectively supported by small organisations working in isolation, and it is our hope that not only will the Muscular Dystrophy Group become better known as a "blanket" organisation but that the Government will realise the pressing need to contribute to the research funds.

Recently Professor Sir John Walton, at the Eighth Symposium on Current Research Into Neuromuscular Diseases, quoted the author Joyce Cary, who suffered from motor neurone disease, on the difficulties of climbing stairs, walking, and, ultimately, writing. It helped to remind those who work with minute fragments of muscle and other tissues that these are human diseases restricting and curtailing the lives of many people. Similarly, we hope that stories like that of Roger Carus will serve to remind us that, however rare the disease, the suffering of one person is no less important than that of many, and that person deserves our attention.

SUSAN BERRY

\section{Muscular Dystrophy Group of}

Great Britain,

\section{Management of acute stroke}

SIR,-Dr W M Garraway and his colleagues (12 April, p 1040) are to be congratulated on their important report of one of the first (if not the first) controlled trials of the value of a stroke unit.

They also make an interesting point concerning those patients with strokes who are transferred from an acute medical unit to a geriatric or rehabilitation unit. They indicate that there are no obvious benefits in terms of earlier discharge from hospital or greater independence for those so transferred. However, they do not give enough information about the factors leading to transfer of these patients. Perhaps they could extend their work with a randomised controlled trial of patients 